\title{
Hearing, voicing and healing: rivers as culturally located and connected
}

\author{
Sandra Wooltorton ${ }^{1}$, Anne Poelina ${ }^{1}$, Laurie Guimond ${ }^{2}$, and Guy Sioui Durand ${ }^{3}$ \\ ${ }^{1}$ The University of Notre Dame Australia - Broome Campus \\ ${ }^{2}$ Universite du Quebec a Montreal \\ ${ }^{3}$ Institution Kiuna Canada
}

July 20, 2021

\begin{abstract}
In this paper a collaborative writing group explores how we, two rivers, express ourselves over time, place and space, our energies long interpreted as veins and arteries carrying the Country's life affirming blood. Voiced as River: I, River, this position reflects a worldview in which interrelationship with living river is normal, and River Spirit is ever-present. It is a position underpinned by Indigenous narratives as riverine expressions of place-based love. At times the paper is also voiced as writing group or individuals, with voices being interchanged where required for smooth reading. We see this as part of the decolonising process, which feels liberating and healing amongst the writers. Each writer is equally valued as co-creator, contributor, narrator and story teller. The two Rivers, being Martuwarra Fitzroy River (Kimberley, Western Australia), and Unamen Shipu Romaine River (North Shore, Québec, Canada) illustrate a common condition of being, through heritage, life, change and possibility. Through stories and voices, the socio-scientific implications of colonisation and lost connections become clear, considering the interaction, the dialogue and the cultural synthesis of living water systems that have always incorporated all life forms into rivers of life. As a way of navigating towards wholeness, Aboriginal knowledge systems and narratives for healing are used to bring together findings of this intercultural river learning journey.
\end{abstract}

\section{Hosted file}

1. Hearing, Voicing and healing - Final July 15 Resubmission.docx available at https: //authorea.com/users/426634/articles/531092-hearing-voicing-and-healing-rivers-asculturally-located-and-connected 

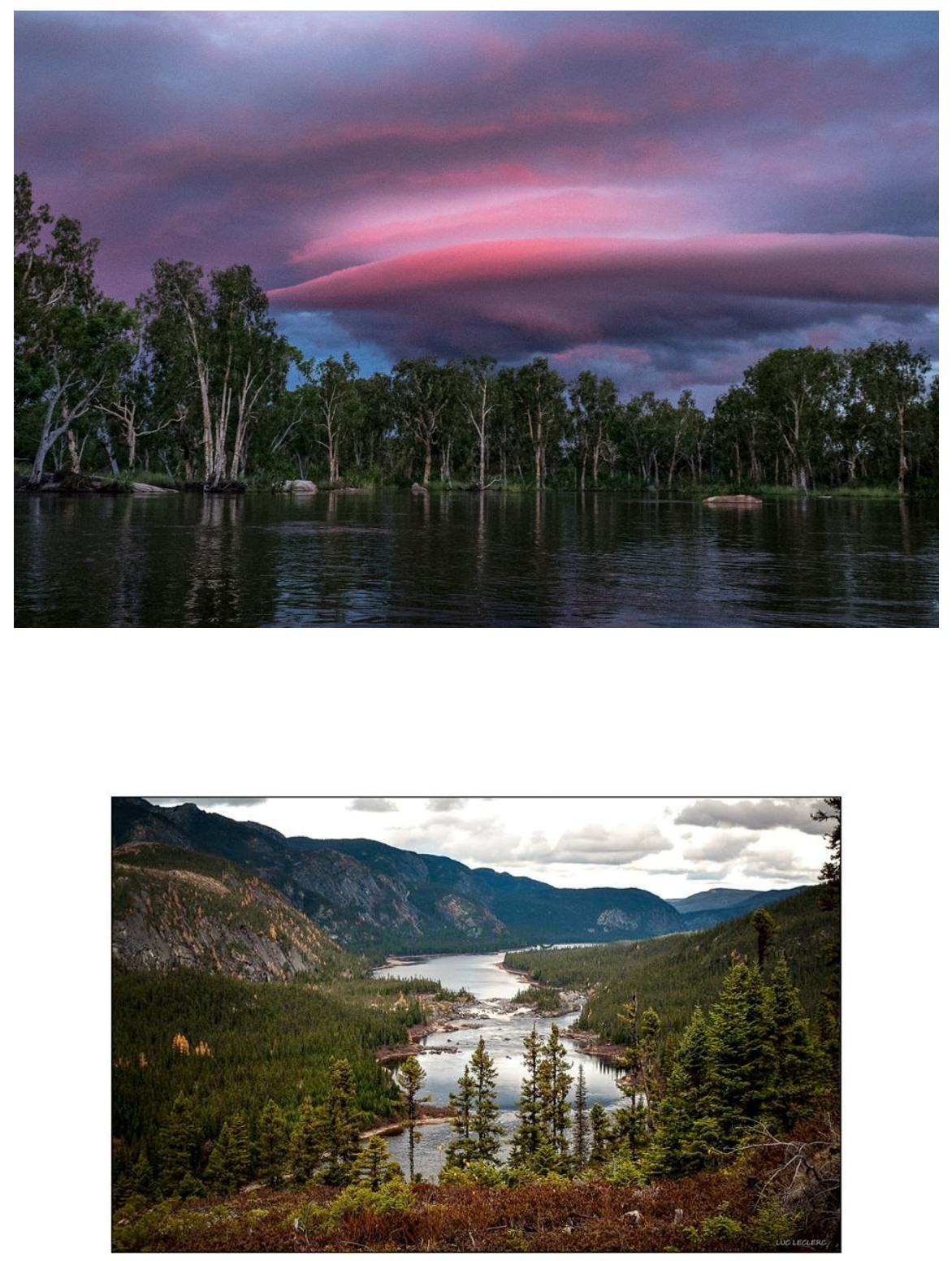


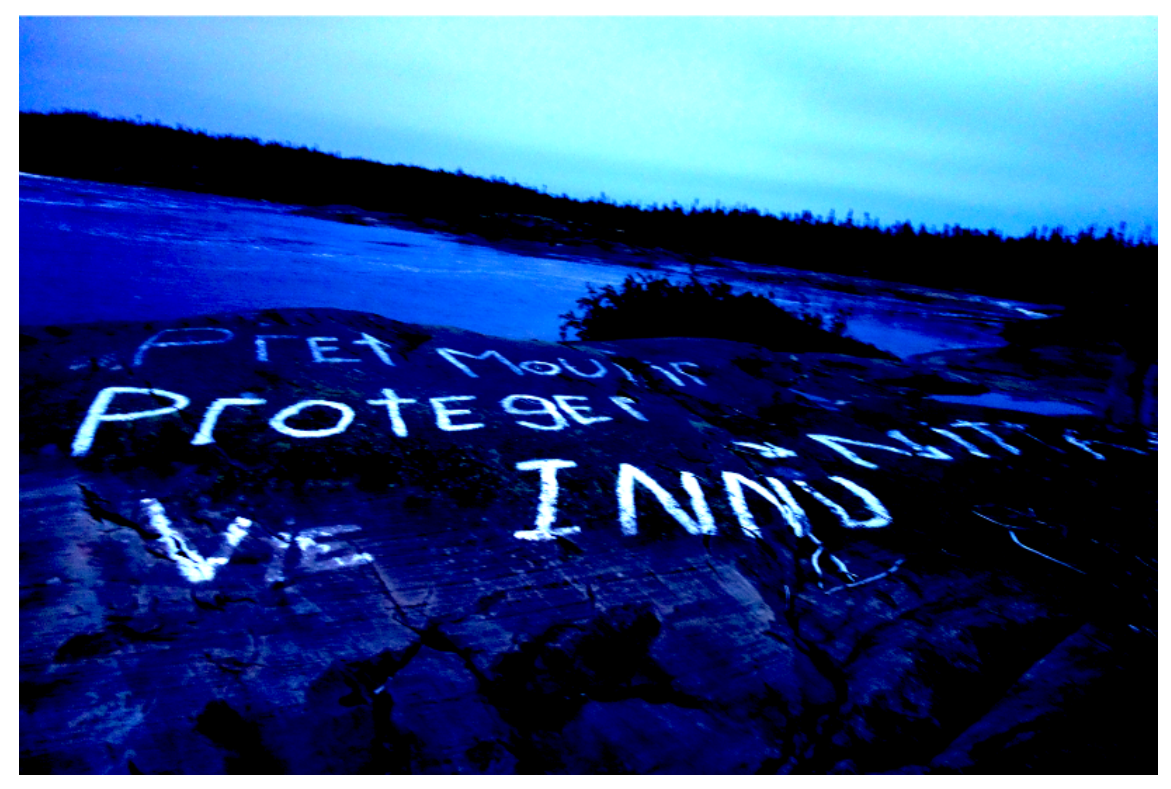

